\title{
Male facial masculinity influences attributions of personality and reproductive strategy
}

\author{
DANIEL J. KRUGER \\ University of Michigan
}

\begin{abstract}
Facial masculinity may be used as a cue in female mate choice, as it reflects the success of the male genotype in its developmental environment. Women may maximize reproductive success by using a conditional strategy favoring highly masculine facial features for short-term relationships and feminized facial features in men for long-term relationships. Three studies examine reactions to masculinized and feminized male facial composites. Properties of the original composite image affect ratings of critical attributes and the magnitude of the differences in ratings between versions undergoing identical processes of geometric manipulation (Study 1). Both men and women attribute personality, behavior, and mating strategies consistent with predictions derived from the good genes and mating trade-off hypotheses (Study 2). Participants accurately grouped behavioral tendencies related to high mating effort/risky strategies and high parenting effort/risk adverse strategies and associated mating effort more so with masculinized faces and parenting effort more so with feminized faces (Study 3). These results indicate that male facial masculinity serves as a visual cue for inferring personality and reproductive strategy.
\end{abstract}

Male facial masculinity may be used as a cue in female mate choice, as it reflects the success of the male genotype in the developmental environment. Men exhibiting these features may have a greater rate of return from mating effort compared to other men and thus may allocate more effort toward mating and less to parental investment. Women may maximize their reproductive success by showing stronger preferences for partners with highly masculine faces for short-term sexual relationships but favor less masculinized faces in prospective long-term relationship partners. Three studies examine whether facial masculinity is related to attributions of male reproductive strategy and contingent female mating strategies.

The author thanks X. T. Wang for his assistance in procuring participants for Study 1.

Correspondence should be addressed to Daniel J. Kruger, University of Michigan, Prevention Research Center and Institute for Social Research, 1420 Washington Heights, Ann Arbor, MI 48109-2029, e-mail: djk2012@gmail.com.

\section{Facial masculinity as a costly signal}

Zahavi's (1975) handicap principle holds that costly behaviors or physical features such as a peacock's large and ornate tail are a signal of physical condition and genetic quality to prospective mates. The immunocompetence handicap model of attractiveness, one variant of the "good gene" model, holds that masculine facial traits in human males, such as prominent brow ridges and large jaws, are honest signals of genetic quality because development of these characteristics is dependent on testosterone. High testosterone levels interfere with proper immune system functioning (Folstad \& Karter, 1992), and thus such signals are difficult to fake due to their high cost. Men who are able to display exaggerated secondary sexual characteristics demonstrate that they have high genetic quality in their developmental environment and having these features is related to reproductive success across species (see Andersson, 1994).

Kokko, Brooks, Jennions, and Morley (2003) caution that a display such as hypermasculinity 
may not have evolved to signal a specific fitness component (immunocompetence), because hypermasculinity could also be related to other fitness components, such as social dominance. Social status is known to be more important as a criterion for selecting male partners than for selecting female partners (e.g., Buss, 1994; Regan, Levin, Sprecher, Christopher, \& Cate, 2000). Indeed, studies have shown that the degree of masculinity in male facial features is directly related to perceptions of social dominance (Berry \& Brownlow, 1989; McArthur \& Apatow, 1983) and that these perceptions correspond with actual social status (Mueller \& Mazur, 1997) and earlier ages of sexual initiation (Mazur, Halpern, \& Udry, 1994). The facial dominance of military cadets at West Point predicted their rank at graduation (Mazur, Mazur, \& Keating, 1984) and the rank that they would eventually achieve (Mueller \& Mazur).

\section{Facial masculinity, attractiveness, and personality}

If facial masculinity is used as a cue in mate choice, the decision process may be influenced by perceptions of physical attractiveness, personality, and/or behavioral tendencies related to mating and parenting. Even newly born infants recognize facial attractiveness, as they show a preference for faces judged to be more attractive by adults (e.g., Langlois et al., 1987; Samuels \& Ewy, 1985). Health status and intelligence can be inferred to some degree from facial photographs (Kalick, Zebrowitz, Langlois, \& Johnson, 1998; Zebrowitz, Hall, Murphy, \& Rhodes, 2002), although the relationship between attractiveness and intelligence may be stronger for those below the median of attractiveness (Zebrowitz \& Rhodes, 2004).

Computer graphic software can masculinize or feminize facial images by taking measurements of the geometrical differences between average male and female face shapes, such as jaw size and lip thickness, and increase or decrease them on a particular face (see PentonVoak, Jacobson, \& Trivers, 2004). Manipulated faces or facial composites can then be used as research stimuli. Facial masculinity in adolescent male faces is associated with both good health and perceptions of health during development (Rhodes, Chan, Zebrowitz, \& Simmons, 2003); however, the relationship between facial masculinity and perceived attractiveness is inconsistent across studies (Penton-Voak et al., 2004; Rhodes et al., 2003). For example, Perrett et al. (1998) found that $50 \%$ feminized male faces were found more attractive than average or $50 \%$ masculinized male faces. Perrett et al. consider this as evidence that female preference for feminized male faces acts as a counterbalance to Fisherian (runaway) sexual selection for extreme male characteristics. The authors also suggest that women may be sensitive to trade-offs between genetic quality and personality characteristics.

Although physiognomy, the attribution of personality to faces, has been categorized with phrenology as a pseudoscience, there is at least some correspondence between inferences of Big 5 personality characteristics from facial portraits and actual personality (see Penton-Voak \& Perrett, 2001). Baby faces with neonatal features such as smaller chins, high eyebrows, and large eyes generally increase attributions of personal warmth, honesty, and sincerity but also naïveté and physical weakness (Berry, 1991; McArthur \& Apatow, 1983). Ratings of male babyishness corresponded with self-reported approachability and warmth and were inversely related to selfreported aggression (Berry \& Brownlow, 1989).

Increasing the masculinity of face shape by $50 \%$ increased perceptions of dominance and masculinity but also decreased perceptions of warmth, emotionality, honesty, cooperativeness, and parental quality (Perrett et al., 1998). Zebrowitz and Rhodes (2004) note that moderate and high degrees of masculinity may indicate better intelligence and health than low masculinity, but high masculinity may not actually indicate an advantage over moderate masculinity. Still, a female preference for high masculinity may be maintained because overgeneralization would be less costly to a woman's reproductive success than a failure to respond (McArthur \& Baron, 1983).

\section{Facial masculinity and conditional female mating strategies}

Men with exaggerated secondary sexual characteristics suggesting good genes may have 
increased mating opportunities. Thus, these men may expend a greater portion of time and resources on mating effort at the expense of long-term investment and paternal care because of the relative reproductive payoffs in the ancestral environment (Gangestad \& Simpson, 2000). Men who provide high-quality genetic investment may be relatively lacking in longterm paternal investment, as high testosterone levels in men are associated with increased levels of infidelity, violence, and divorce (Booth \& Dabbs, 1993). Hence, a preference for feminized male faces could be partly due to the association of masculinized male faces and adverse behavioral patterns (Penton-Voak \& Perrett, 2001).

\section{Masculinity and conditional mating strategies}

Highly masculine features may be differentially valued across contexts because women may use a conditional mating strategy based on life history factors and the type of the relationship sought (Gangestad \& Simpson, 2000). For example, potential genetic investment may be more highly valued for a short-term relationship, whereas potential paternal investment may be more highly valued for a long-term relationship. As evidence for this possibility, data show that women's preferences for facial masculinity are increased during the fertile phase of their menstrual cycle, especially when they are considering cheating on their partners (an extra-pair copulation [EPC]; Penton-Voak \& Perrett, 2001; Penton-Voak et al., 1999). In Jamaica, parasite load is higher, medical care is less common, and male parental investment is lower than in Britain. Thus, Jamaican women may value cues of potential genetic quality more and parental investment less than their British counterparts. In fact, Jamaican women preferred a greater degree of male facial masculinity than women in Britain (Penton-Voak et al., 2004). Such ecological factors may underlie cultural differences in preferences for personality characteristics related to the tradeoff between parental and genetic investment.

\section{Current research questions}

Manipulating the masculinity of male faces may affect both perceived physical attractive- ness and perceived age, as facial masculinity is a secondary sexual characteristic signaling physical maturity. Indeed, there is a crosscultural preference for men of a moderately older age (Buss, 1994). This preference could relate to physical strength and the ability for physical fighting with other men, avoiding or defending against predators, and/or capturing prey without injury, as well as the fact that older men are likely to have higher social status and greater control over resources. It is assumed that masculinity and femininity represent opposite portions of the same dimension; this is the way in which facial images are operationalized. Feminine attractiveness is known to be related to the conservation of neonatal features (Cunningham, 1986; Cunningham, Roberts, Wu, Barbee, \& Druen, 1995).

One possible explanation for inconsistencies in the literature on facial masculinity is variance in the stimuli used across studies. Blanton and Jaccard (2006) have recently focused attention on potentially problematic issues with arbitrary metrics in psychological research. In order to properly test the relationship between facial masculinity and attributions of personality and reproductive strategies, it is necessary to verify the assumptions underlying research using geometric manipulations of faces or facial composites. In prior studies, the degrees of masculinization and feminization are defined by geometric manipulations of baseline stimuli. The neutral point is assumed to be the composite image of sampled faces. Standards or norms for real-world facial masculinity are unknown, and subjective interpretations may be influenced by characteristics of baseline stimuli in addition to manipulations. The face validity of stimuli in previous studies (e.g., Penton-Voak et al., 2003) is ambiguous, as the properties of baseline facial composites appear to influence relative masculinity. Thus, the first study serves as a manipulation check to verify assumptions about subjective masculinity, femininity, attractiveness, and estimated age of manipulated images. To contrast with the assumption of the proportionality of geometric manipulation and attributed properties, the following hypotheses are proposed. For three sets of masculinized and feminized facial composites: 
H1: Ratings of attractiveness, age, masculinity, and femininity will vary based on the facial composite used to create masculinized and feminized stimuli.

$\mathrm{H} 2$ : The effect size of the differences in ratings between masculinized and feminized stimuli will vary depending on the facial composite used to create the stimuli.

\section{Gender differences in sensitivity to facial masculinity}

Women may be more sensitive to differences in facial masculinity because this would facilitate a contingent mating strategy based on relationship length. Previous research has found that women are more accurate than men in inferring personality from facial characteristics (Ambady, Hallahan, \& Rosenthal, 1995), which would have obvious benefits such as protecting against mate desertion (Penton-Voak \& Perrett, 2001), known to be more likely in men (Symons, 1979). Men should also show sensitivity to facial masculinity, as this would aid their ability to gauge the strategies of their male conspecifics, because (a) it would aid them in male-male competition for resources, social status, and mates; (b) the potential impact on social alliances that protect and enhance reproductive success; (c) the threat of cuckoldry; and (d) inclusive fitness through female kin. Still, a gender difference in sensitivity to male facial masculinity is expected.

H3: Women's ratings of attractiveness, age, masculinity, and femininity will show more discrimination based on geometric manipulations of facial masculinity than men's ratings.

\section{Study 1 Method}

\section{Participants}

Students ( $N=448,316$ female) from a large midwestern American university participated in an online study to fulfill a course require- ment. The mean age was 20.6 years $(S D=$ 4.3). Data from all studies were stored on a secure server with password protection and data encryption during transmission. Participants generated a unique code that was used to track participation and prevent duplication of data; participants' names were not associated with the data provided.

\section{Materials and procedure}

Stimuli included the 50\% masculinized and $50 \%$ feminized male facial composites (of 18-26 individual faces) from rows 1,2 , and 4 of the stimuli in Penton-Voak et al. (2003). Three of the four rows of Caucasian facial composites were randomly selected to reduce differences across stimuli. The six facial composites were presented in a random order followed by three questions on a 1 (not at all) to 7 (extremely) point scale: How attractive do you think this person is? How masculine do you think this person is? How feminine do you think this person is? Participants also estimated the age of each target. A 3 (facial composite) $\times 2$ (masculinized vs. feminized version) $\times 2$ (participant gender) $\times 4$ (rating scale) mixedmodel multivariate analyses of variance (MANOVA) provided results for the combined dependent measures. Follow-up univariate analyses, 3 (facial composite) $\times 2$ (masculinized vs. feminized version) $\times 2$ (participant gender) mixed-model analyses of variance (ANOVA), assessed each dependent measure separately. Some may argue that facial composites should be treated as a random effect, as they may reside on a continuum of masculinity (see Jackson \& Brashers, 1994). Unfortunately, it is not possible to conduct a $3 \times 2 \times 2 \times 4$ MANOVA for mixed-model designs with crossed random factors in currently available statistical software.

\section{Study 1 Results}

The average correlation among dependent variables was .24 . The MANOVA revealed a significant effect of facial composite across rating scales $F(2,10,571)=526.0, p<.001$. H1 was supported for ratings of estimated age, $F(2,848)=336.1, p<.001$; masculinity, 
$F(2,862)=362.3, p<.001 ;$ and femininity, $F(2,852)=254.4, p<.001$. Some composites were rated as more masculine, more feminine, and older than others, independent of version. Although there was no simple main effect for the baseline facial composite used on attractiveness, there were two-way interactions between composite and participant gender, $F(2,872)=17.3, p<.001$, and composite and version, $F(2,872)=35.8, p<.001$, and a three-way interaction between composite, participant gender, and version, $F(2,872)=$ $4.8, p=.008$, on ratings of attractiveness. This indicates that the facial composite used will affect ratings of all four dependent variables.

$\mathrm{H} 2$ was supported. The MANOVA revealed a significant interaction between facial composite and version across rating scales $F(2$, $10,571)=51.6, p<.001$. There was considerable variation in effect sizes of the differences between the masculinized and feminized versions of each facial composite (see Table 1). Cohen (1988) outlines small, $d=.20$, medium, $d=.50$, and large, $d=.80$, effect sizes for the behavioral sciences. Effect sizes ranged from nonsignificant to .63 for differences in age estimates, from nonsignificant to .70 for differences in attractiveness estimates, from .48 to .91 for differences in femininity, and from .36 to .90 for differences in masculinity.

The MANOVA revealed a significant three-way interaction between gender, facial composite, and version, $F(2,10,571)=6.99$, $p<.001$. H3 was supported for ratings of attractiveness, $F(1,872)=17.3, p<.001$; women generally rated the faces as more attractive than men but also showed more discrimination between masculinized and feminized versions. Women showed more discrimination in responses for version in ratings of masculinity, $F(1,862)=7.5, p=.006$ and femininity, $F(1,848)=5.6, p=.018$, but the gender by version interaction only approached significance for estimated age, $F(1,852)=$ $3.5, p=.062$.

\section{Study 2}

The mating trade-off hypothesis predicts that women's partner preferences should be related to the length of relationship and expectations for genetic and parental investments. If facial masculinity is used as a cue in female mate choice, then attributions related to male personality and reproductive strategy may be based in part on facial masculinity. There are individual differences in male mating effort (Rowe, Vazsonyi, \& Figueredo, 1997) and evidence that some males specialize in a short-term mating strategy, seeking to mate with a large number of partners (e.g., Belsky, Steinberg, \& Draper, 1991). These men attract women by showing that they are highly competitive, dominant, brave, aggressive, high in risk taking, and rebellious and will give women sons who show the same characteristics. Other men attract women because they are compassionate, kind, romantic, and industrious, features that suggest the ability and willingness to invest in the relationship and parentally invest in potential children. Crossculturally, men show distinct clusters of personality traits that reflect the attributes women respectively value in men for short- and longterm relationships (see Draper \& Belsky, 1990).

Because of the relative payoffs for mating and parental effort discussed in the introductory paragraph, the person represented by the masculinized face is likely to be perceived as higher in mating effort and lower in parenting effort compared to the feminized version. Mating effort includes high-risk behaviors that may demonstrate physical prowess and also facilitate competition for social status and resource control. Male social status shows a positive relationship to reproductive success across a wide variety of societies (Hopcroft, 2006). Consistent with the mating trade-off hypothesis, participants should attribute greater tendencies for risky and competitive behaviors and lesser tendencies for parental investment to highly masculine faces.

Women may maximize reproductive success by using a conditional strategy favoring highly masculine men for short-term relationships and less masculine men for long-term relationships (Gangestad \& Simpson, 2000). Although women have serial pregnancies and thus do benefit proportionally to the number of partners as would men, women do occasionally undertake short-term relationships with 
Table 1. Average (SD) ratings of masculinized and feminized facial composites

\begin{tabular}{|c|c|c|c|c|c|}
\hline \multirow[b]{2}{*}{ Row } & \multirow[b]{2}{*}{ Variable } & \multirow[b]{2}{*}{ Gender } & \multicolumn{2}{|c|}{$M \pm S D$} & \multirow[b]{2}{*}{$d$} \\
\hline & & & Masculinized & Feminized & \\
\hline \multirow[t]{8}{*}{1} & \multirow[t]{2}{*}{ Age } & Females & $22.5 \pm 2.8$ & $21.5 \pm 2.8$ & $.44 * * *$ \\
\hline & & Males & $22.3 \pm 3.0$ & $21.6 \pm 3.6$ & $.27 * *$ \\
\hline & \multirow[t]{2}{*}{ Attractiveness } & Females & $3.9 \pm 1.6$ & $3.8 \pm 1.6$ & .08 \\
\hline & & Males & $3.0 \pm 1.6$ & $3.0 \pm 1.5$ & .03 \\
\hline & \multirow[t]{2}{*}{ Femininity } & Females & $1.7 \pm .9$ & $2.3 \pm 1.2$ & $.53 * * *$ \\
\hline & & Males & $1.9 \pm 1.1$ & $2.5 \pm 1.3$ & $.48 * * *$ \\
\hline & \multirow[t]{2}{*}{ Masculinity } & Females & $5.6 \pm 1.3$ & $5.0 \pm 1.3$ & $.49 * * *$ \\
\hline & & Males & $5.7 \pm 1.3$ & $4.8 \pm 1.4$ & $.75 * * *$ \\
\hline \multirow[t]{8}{*}{2} & \multirow[t]{2}{*}{ Age } & Females & $20.7 \pm 2.6$ & $19.1 \pm 2.6$ & $.63 * * *$ \\
\hline & & Males & $20.6 \pm 2.4$ & $19.7 \pm 2.9$ & $.32 * * *$ \\
\hline & \multirow[t]{2}{*}{ Attractiveness } & Females & $4.1 \pm 1.3$ & $3.2 \pm 1.3$ & $.70 * * *$ \\
\hline & & Males & $3.3 \pm 1.6$ & $3.0 \pm 1.4$ & $.23 * *$ \\
\hline & \multirow[t]{2}{*}{ Femininity } & Females & $2.4 \pm 1.1$ & $3.3 \pm 1.5$ & $.70 * * *$ \\
\hline & & Males & $2.3 \pm 1.1$ & $3.8 \pm 1.4$ & $.91 * * *$ \\
\hline & \multirow[t]{2}{*}{ Masculinity } & Females & $4.8 \pm 1.1$ & $3.8 \pm 1.3$ & $.84 * * *$ \\
\hline & & Males & $4.9 \pm 1.4$ & $3.5 \pm 1.3$ & $.90 * * *$ \\
\hline \multirow[t]{8}{*}{4} & \multirow[t]{2}{*}{ Age } & Females & $19.3 \pm 2.4$ & $19.2 \pm 2.5$ & .04 \\
\hline & & Males & $19.2 \pm 2.5$ & $19.1 \pm 2.3$ & .09 \\
\hline & \multirow[t]{2}{*}{ Attractiveness } & Females & $3.7 \pm 1.4$ & $3.7 \pm 1.2$ & .02 \\
\hline & & Males & $3.1 \pm 1.5$ & $3.4 \pm 1.5$ & $.31 * * *$ \\
\hline & \multirow[t]{2}{*}{ Femininity } & Females & $2.7 \pm 1.3$ & $3.5 \pm 1.4$ & $.58 * * *$ \\
\hline & & Males & $3.0 \pm 1.4$ & $3.9 \pm 1.4$ & $.60 * * *$ \\
\hline & \multirow[t]{2}{*}{ Masculinity } & Females & $4.3 \pm 1.3$ & $3.8 \pm 1.2$ & $.36^{* * *}$ \\
\hline & & Males & $4.2 \pm 1.4$ & $3.7 \pm 1.3$ & $.42 * * *$ \\
\hline
\end{tabular}

Note. ${ }^{* *} p<.01 . * * * p<.001$.

men (see Mealey, 2000). Around 9\%-13\% of children have genetic fathers different from their putative fathers, according to DNA analyses (Baker \& Bellis, 1995). Fisher (1930) suggested that women may cheat on their partner (with an EPC) to obtain genes for offspring from men with high-quality phenotypes in the present environment. Consistent with the mating trade-off hypothesis, preferences for masculinized and feminized male faces should follow from expectations for potential genetic and parental investments. Women should prefer the masculinized version for sexual relationships and EPCs but should prefer the feminized version for marriage.

Participants should be wary of allowing highly masculinized characters into circumstances that could adversely impact participants' inclusive fitness, cuckolding for men and mate defection for both men and women. Men should prefer the feminized version to accompany their girlfriend on weekend trip to another city. Both men and women should prefer the feminized version as a son-in-law because "he" would be less likely to desert their daughter and reduce inclusive fitness though the aversive effects of father absence (e.g., Draper \& Harpending, 1982, 1988) and possible diversion of resources that could be otherwise allocated to additional kin. Women should also predict that their parents would prefer them to date the feminized version, as "fatherless" grandchildren may consume the resources of maternal grandparents, which could have been expended on other offspring to enhance inclusive fitness.

It is not currently known which specific attributions underlie women's conditional 
mating strategies for facial masculinity. An inherent tendency toward an adaptive behavior will spread regardless of the subjective mental experience (or nonexperience) of the individual, as long as the action reliably occurs. From an evolutionary perspective, it is not necessary for women to consciously recognize the potential genetic benefits resulting from sex with men with exaggerated secondary sexual characteristics. If women are cognizant of the potential genetic benefits of mating with a man with higher facial masculinity, they should select the masculinized version for a sperm donor. Scheib (1994) found that attributes women thought would be passed onto offspring were more important when selecting a sperm donor than a long-term mate. For men, whose reproductive success would not be affected by this decision, the choice between masculinized and feminized versions could be arbitrary but men might select the feminized version because of the increased threat of competition from men with exaggerated secondary sexual characteristics. As described above, the hypotheses for Study 2 are the following:

H4: Facial masculinity will be directly related to perceived tendencies for risky and competitive behaviors.

H5: Facial masculinity will be directly related to perceived mating effort.

H6: Facial masculinity will be inversely related to perceived potential parental investment.

H7: Women will favor facial masculinity for partners in sexual relationships and EPCs, but facial femininity for partners for marriage.

H8: Participants will favor facial femininity for circumstances that potentially threaten participants' inclusive fitness (cuckoldry and mate defection).

H9: Women's choices will indicate explicit recognition of the relationship between high facial masculinity and genetic quality.

\section{Study 2 Method}

\section{Participants}

Students $(N=246,131$ female $)$ from a large midwestern American university (a different university from Study 1) participated in an online study. The mean age was 19.3 years $(S D=2.0)$.

\section{Materials and procedure}

Participants viewed the 50\% masculinized and feminized versions of the facial composite from row 4 of male facial composites in Penton-Voak et al. (2003) next to each other on the same survey page and were asked to choose the appropriate version for each of several items on personality and behavioral attributes and relationship choices. These composites were used based on the psychometric properties of the stimuli found in Study 1. Participants did not perceive an age difference, females did not perceive a difference in attractiveness, and effect sizes between the two versions of this facial composite for masculinity and femininity were moderate. Five items represented risky and competitive behaviors (e.g., Which person do you think would frequently challenge his boss? Which person do you think gets into more physical fights?). Four items represented mating effort (e.g., Which person do you think would sleep with more women in his lifetime? Which person do you think would be more likely to hit on [you/your girlfriend] even if he knew that [you/she] had a boyfriend?). Four items represented paternal investment (e.g., Which person would be better at taking care of children? Assuming each had the same income, which person do you think would provide more resources for his family?). Scales were computed using choice values of +1 for masculinized version and -1 for feminized version for each item.

Women picked the version they would prefer for brief sexual relations, marriage, an EPC, a sperm donor, and which person their parents would prefer them to date. Men picked the version they would prefer to accompany their girlfriends on a weekend trip to another city. All participants indicated which version they would prefer to be engaged to a hypothetical 
25-year-old daughter. Chi-square tests uncovered preferences for each item.

\section{Study 2 Results}

The scale items demonstrated excellent reliability (Cronbach's alpha was .834 for risky and competitive behaviors, .873 for mating effort, and .805 for paternal investment). Results supported H4, H5, and H6; highly masculine faces were more likely to be selected for risky and competitive behaviors, $\chi^{2}(1)=382.6, p<$ .001 (95\% CI 2.38-3.19), and mating effort, $\chi^{2}(1)=166.1, p<.001$ (95\% CI 1.92-2.62), and less likely to be selected for parental investment, $\chi^{2}(1)=220.7, p<.001(95 \%$ CI -2.225 to -1.54$)$. H7 was partially supported; women preferred the masculinized version for EPCs and the feminized version for marriage but had no preference for sexual relationships (see Table 2). H8 was supported; both men and women preferred the feminized version as a son-in-law and men preferred the feminized version to accompany their girlfriends on a weekend trip to another city. H9 was not supported; neither gender had a preference for a sperm donor.

The results of Study 2 suggest that people readily attribute patterns of behavior reflecting high mating effort and high parenting effort strategies to men based on their degree of facial masculinity. However, the forced choice

Table 2. Percentage of male and female participants selecting the masculinized version

\begin{tabular}{lcc}
\hline \hline Item & Male & Female \\
\hline Prefer for EPC & - & $66^{*}$ \\
Prefer to marry & - & $37^{*}$ \\
Parents would & - & $29^{*}$ \\
$\quad$ prefer you to date & & \\
Prefer for sexual relations & - & 57 \\
Prefer to date & - & 50 \\
Prefer as a sperm donor & 42 & 46 \\
Prefer as son-in-law & $23^{*}$ & $27^{*}$ \\
Prefer to accompany & $23^{*}$ & - \\
$\quad$ girlfriend on weekend trip & & \\
\hline \hline
\end{tabular}

Note. $\mathrm{EPC}=$ extra-pair copulation. - indicates question not asked.

$* p<.05$. design of the study limits the ability to gauge the degree to which participants would make these attributions separately for each version of facial composite. Also, only one facial composite was tested, despite the demonstrated variance in response to the composites in Study 1. Thus, a third study gathered more precise data on attributes of reproductive strategies separately for masculinized and feminized versions of the three facial composites from Study 1 . Rating scales were developed to indicate nine attributes of high mating effort/risky strategies (where masculinized versions should be rated higher) and five attributes of high parenting effort/risk adverse strategies (where feminized versions should be rated higher; see Table 3). Study 3 tests the following hypotheses:

H10: Mating effort/risky strategies and parenting effort/risk adverse strategies will form two distinct but inversely related dimensions.

H11: The effect size of version on ratings of mating effort/risky strategies and parenting effort/risk adverse strategies will differ by facial composite.

H12: Women's ratings of mating effort/ risky strategies and parenting effort/risk adverse strategies will show more discrimination than men's ratings based on geometric manipulations of facial masculinity.

H13: Facial masculinity will be directly related to perceptions of mating effort and risky strategies.

H14: Facial femininity will be inversely related to perceptions of mating effort and risky strategies.

H15: Facial masculinity will be inversely related to perceptions of potential parenting effort and risk adverse strategies.

H16: Facial femininity will be directly related to perceptions of potential parenting effort and risk adverse strategies. 
Table 3. Standardized factor loadings in Study 3

\begin{tabular}{lcc}
\hline \hline Item & Parenting & Mating \\
\hline Be a good husband & .83 & \\
Be caring and emotionally supportive in a long-term relationship & .80 & \\
Be great with children & .79 & \\
Use nearly all of his income to support his family & .79 & \\
Work hard at his job even though he did not like it & .72 & .84 \\
Knowingly hit on someone else's girlfriend & & .84 \\
Get into physical fights & & .83 \\
Cheat on his partner & & .67 \\
Frequently challenge his boss & .50 \\
Sleep with a large number of women in his lifetime & .44 \\
Be attractive to women for a brief sexual relationship & .40 \\
Wear flashy clothes & & .31 \\
Be lots of fun at parties & & \\
\hline
\end{tabular}

Note. All loadings are statistically significant.

\section{Study 3 Method}

\section{Participants}

Additional students $(N=160,102$ female $)$ from the midwestern American university in Study 2 participated in an online study. The mean age was 18.7 years $(S D=.8)$.

\section{Materials and procedure}

Participants viewed the masculinized and feminized versions of the three facial composites from Study 1 in a randomized order, each on a separate survey page. Participants read the phrase "Please look at the image of the man below and rate how likely it is that he would ..." and rated each face using 7-point bipolar scales on 14 items related to life history and reproductive strategies (see Table 3). Responses were entered into confirmatory factor analysis (CFA) of the two hypothesized scales. Scale scores were calculated by summing appropriate items. Mixed-model ANOVAs, 3 (facial composite) $\times 2$ (masculinized vs. feminized version) $\times 2$ (participant gender), examined patterns of scale scores. Hierarchical linear models (HLMs; Raudenbush \& Bryk, 2002) examined the relationship between the mean ratings of masculinity and femininity from participants in Study 1 to predict scale scores computed for individual responses of participants in Study 3. Because Study 1 and Study 3 are ratings from two separate and mutually exclusive samples of individuals, repeated measures analyses are not possible. HLM takes a summary characteristic from Study 1 (e.g., mean masculinity rating) and predicts individual responses from individuals sampled in Study 3 (e.g., perceived parenting effort).

\section{Study 3 Results}

H10 was supported. The CFA indicated that the two-factor model separating mating effort/risky strategies and parenting effort/risk adverse strategies had a good fit to the data, $\chi^{2}(44)=$ 323.95; GFI (Goodness of Fit Index) $=.95$; CFI (Comparative Fit Index), NFI (Normed Fit Index), and IFI (Incremental Fit Index) $=.96$; and critical $N=194$. All items loaded significantly on the expected factor in the anticipated direction (for standardized factor loadings, equivalent to correlation coefficients, see Table 3). The two factors were inversely related, with $20 \%$ overlap in variance. The solution for a one-factor comparison model did not converge after 10,000 iterations. Modification indexes suggested the elimination of the "Go to jail" item. Cronbach's alphas were .872 for the scale of mating items and .894 for the scale of parenting items excluding "Go to jail."

H11 was supported for both dimensions. The effect size of version differed by facial 
composite for mating effort/risky strategies, $F(2,316)=4.255, p=.015$, and for parenting effort/risk adverse strategies, $F(2,316)=$ 8.547, $p<.001$ (see Table 4). H12 was not supported; no interactions between gender and version were found. H13 was supported; masculinized versions scored higher than feminized versions on mating effort/risky strategies, $F(1,316)=121.195, p<.001$, and as noted above the magnitude of the effect varied by facial composite. HLM indicated that perceived masculinity in Study 1 was directly related to perceived mating effort, $t(958)=$ $13.805, p<.001$, in Study 3. H14 was supported; HLM indicated that perceived femininity in Study 1 was inversely related to perceived mating effort, $t(958)=14.972$, $p<.001$, in Study 3. H15 was supported; feminized versions scored higher than masculinized versions on parenting effort/risk adverse strategies, $F(1,316)=122.672, p<.001$, and as noted above the magnitude of the effect varied by facial composite. HLM indicated that perceived masculinity in Study 1 was inversely related to perceived parenting effort, $t(958)=11.486, p<.001$, in Study 3. H16 was supported; HLM indicated that perceived femininity in Study 1 was directly related to perceived parenting effort, $t(958)=12.257$, $p<.001$, in Study 3 .

\section{Discussion}

Facial masculinity appears to serve as a visual cue for inferring male personality and reproductive strategy. In Studies 2 and 3, partici- pants attribute personality, behavior, and mating strategies consistent with predictions derived from the mating trade-off hypothesis based on the degree of facial masculinity. The prediction that women used facial masculinity as a cue in conditional mating strategies received mixed support.

Highly masculine faces are associated with riskier and more competitive behavioral strategies, higher mating effort, and lower parenting effort in comparison with less masculine faces. Those researching relationships should be aware that a man's personality may be prejudged based on his physical appearance. It is remarkable that rich personality and behavioral descriptions are attributed based on minor physiological differences. The ability to predict male personality attributes and behavioral strategies from a readily available and efficient cue such as facial masculinity is likely to have benefited the survival and reproduction of human ancestors. As noted in the introductory paragraph, previous research has verified the connection between testosterone levels, which influence facial masculinity, and reproductive strategy (Booth \& Dabbs, 1993). This indicates that such stereotyped inferences hold a kernel of truth.

There was mixed support for the notion that women use facial masculinity for conditional mating strategies consistent with the mating trade-off hypothesis. As found in previous studies, women preferred a highly masculine partner for EPCs. Women favored a less masculine partner for marriage; however, they did not exhibit a preference for sexual relationships.

Table 4. Average (SD) scale scores of masculinized and feminized facial composites

\begin{tabular}{llccc}
\hline \hline \multirow{2}{*}{ Row } & & \multicolumn{2}{c}{$M \pm S D$} \\
\cline { 3 - 4 } 1 & Scale & Masculinized & Feminized & $d$ \\
\hline \multirow{2}{*}{2} & Parenting & $3.42 \pm 1.14$ & $4.30 \pm .89$ & $.71^{* * *}$ \\
& Mating & $4.53 \pm 1.00$ & $4.11 \pm .76$ & $.45^{* * *}$ \\
3 & Parenting & $4.40 \pm .99$ & $4.79 \pm .99$ & $.34^{* * *}$ \\
& Mating & $4.06 \pm .91$ & $3.43 \pm .92$ & $.66^{* * *}$ \\
& Parenting & $3.82 \pm .91$ & $4.51 \pm .96$ & $.70^{* * *}$ \\
& Mating & $4.26 \pm .95$ & $3.58 \pm .89$ & $.79^{* * *}$ \\
\hline \hline
\end{tabular}

Note. ${ }^{* * *} p<.001$. 
The evidence for conditional mating strategies is limited, as these choices were made in one study in a comparison of two faces matched for attractiveness. It is possible that physical attractiveness mediates desirability for brief sexual relationships, and thus future studies are needed to reexamine this relationship with additional stimuli.

Results do not support the notion that women interpret high facial masculinity as an indicator of good genes that would be beneficial for their offspring, as no preference was expressed for a sperm donor. An accurate understanding of genetic inheritance may have been useful but was not necessary for reproductive success in our ancestral environment. Partner selection may have been based on properties such as physical attractiveness, social status, resource holdings, and interpersonal qualities, rather than an explicit understanding of genetic inheritance.

There was some evidence that women were more sensitive to differences in facial masculinity and femininity from Study 1, but this effect was not replicated in Study 3. It is possible that both women and men are highly sensitive to facial masculinity because of the potential impact of relationship choices on reproductive success. Men may use facial masculinity to: gauge competitors in male-male competition for resources and social status, estimate cuckoldry risks, match female kin with substantially investing partners, and select social alliance partners.

Other preferences and attributions were consistent with predictions. Both men and women recognized the potential costs of defection in men with exaggerated secondary sexual characteristics, choosing the feminine version for engagement to a hypothetical daughter. A previous study found that highly masculine faces were perceived to represent lower "quality as a parent" (Perrett et al., 1998).

Masculinized faces have been associated with social dominance (McArthur \& Apatow, 1983; Mueller \& Mazur, 1997) and in the current study were rated more likely to compete for social status through physical fights and challenging social superiors. Participants thought that the less masculine version would be better at taking care of children and provide more resources to his family. It is not surprising that men preferred the less masculine version to accompany their girlfriends on a weekend trip to another city, and women thought that their parents would prefer him as her dating partner.

The results of Study 3 indicate that participants accurately associate the traits and behavioral tendencies in high mating effort/ risky strategies and high parenting effort/risk adverse strategies. The high reliability of the measurement scales for these strategies demonstrates their usefulness for future research. As expected, masculinized facial composites scored higher on high mating effort/risky strategies and lower on high parenting effort/risk adverse strategies than feminized versions. These results buttress the findings in Study 2, ameliorating concerns with the forced choice methodology and use of limited stimuli. Confirming predictions, the degrees of perceived femininity and perceived masculinity in Study 1 were related to attributions of reproductive strategies in Study 3.

Results indicated that perceptions of facial composites are affected by differences in the original properties of the composites, in addition to graphical manipulations. In Study 1, facial composites that were $50 \%$ masculinized from baseline were perceived as more feminine than other facial composites that were $50 \%$ feminized from baseline, and vice versa. The effect sizes of identical geometric manipulations also varied by facial composite. This pattern of results was replicated in Study 3. A researcher using just one facial composite to test a good gene model of attractiveness could find no support with two of the three facial composites analyzed in this study. It is recommended that experimenters pretest their stimuli to check perceptions of the properties under examination, especially when using multiple stimuli derived from different facial composites. Unverified stimuli properties may be responsible for some of the inconsistencies between previous research projects.

These studies extend the literature on facial masculinity by demonstrating that both women and men use male facial masculinity to infer behavioral and reproductive strategies. Both women and men also generally respond 
to men with high and low facial masculinity in ways that could be expected to benefit their own reproductive success. Although there was no explicit recognition of the good genes presumed to underlie exaggerated secondary sexual characteristics, participants were aware of the enhanced mating opportunities available to men with these characteristics and the consequent shift of effort from paternal investment to mate acquisition.

\section{References}

Ambady, N., Hallahan, M., \& Rosenthal, R. (1995). On judging and being judged accurately in zero-acquaintance situations. Journal of Personality and Social Psychology, 55, 387-395.

Andersson, M. (1994). Sexual selection. Princeton, NJ: Princeton University Press.

Baker, R. R., \& Bellis, M. A. (1995). Human sperm competition: Copulation, masturbation and infidelity. London: Chapman and Hall.

Belsky, J., Steinberg, L., \& Draper, P. (1991). Childhood experience, interpersonal development, and reproductive strategy: An evolutionary theory of socialization. Child Development, 62, 647-670.

Berry, D. S. (1991). Attractive faces are not all created equal: Joint effects of facial babyishness and attractiveness on social perception. Personality and Social Psychology Bulletin, 17, 523-533.

Berry, D. S., \& Brownlow, S. (1989). Were the physiognomists right? Personality correlates of facial babyishness. Personality and Social Psychology Bulletin, 15, 266-279.

Blanton, H., \& Jaccard, J. (2006). Arbitrary metrics in psychology. American Psychologist, 61, 27-41.

Booth, A., \& Dabbs, J. (1993). Testosterone and men's marriages. Social Forces, 72, 463-477.

Buss, D. M. (1994). The evolution of desire: Strategies of human mating. New York: Basic Books.

Cohen, J. (1988). Statistical power analysis for the behavioral sciences (2nd ed.). New York: Academic Press.

Cunningham, M. R. (1986). Measuring the physical in physical attractiveness: Quasi-experiments on the sociobiology of female facial beauty. Journal of Personality and Social Psychology, 50, 925-935.

Cunningham, M. R., Roberts, A. R., Wu, C., Barbee, A. P., $\&$ Druen, P. B. (1995). Their ideas of beauty are, on the whole, the same as ours: Consistency and variability in the cross-cultural perception of female physical attractiveness. Journal of Personality and Social Psychology, 68, 261-279.

Draper, P., \& Belsky, J. (1990). Personality development in evolutionary perspective. Journal of Personality, $58,141-161$.

Draper, P., \& Harpending, H. (1982). Father absence and reproductive strategy: An evolutionary perspective. Journal of Anthropological Research, 38, 252-273.

Draper, P., \& Harpending, H. (1988). A sociobiological perspective on the development of human reproductive strategies. In K. B. MacDonald (Ed.), Sociobiological perspectives on human development (pp. 340-372). New York: Springer.
Fisher, R. A. (1930). The genetical theory of natural selection. Oxford, UK: Oxford University Press.

Folstad, I., \& Karter, A. J. (1992). Parasites, bright males, and the immunocompetence handicap. American Naturalist, 139, 603-622.

Gangestad, S. W., \& Simpson, J. A. (2000). The evolution of human mating: Trade-offs and strategic pluralism. Behavioral and Brain Sciences, 23, 573-644.

Hopcroft, R. L. (2006). Sex, status, and reproductive success in the contemporary United States. Evolution and Human Behavior, 27, 104-120.

Jackson, S., \& Brashers, D. E. (1994). Random factors in ANOVA. Thousand Oaks, CA: Sage.

Kalick, S. M., Zebrowitz, L. A., Langlois, J. H., \& Johnson, R. M. (1998). Does human facial attractiveness honestly advertise health? Longitudinal data on an evolutionary question. Psychological Science, 9, 8-13.

Kokko, H., Brooks, R., Jennions, M. D., \& Morley, J. (2003). The evolution of mate choice and mating biases. Proceedings of the Royal Society of London, Series B, 270, 653-664.

Langlois, J. H., Roggman, L. A., Casey, R. J., Ritter, J. M., Rieser-Danner, L. A., \& Jenkins, V. Y. (1987). Infant preferences for attractive faces: Rudiments of a stereotype? Developmental Psychology, 23, 363-369.

Mazur, A., Halpern, C., \& Udry, J. (1994). Dominant looking male teenagers copulate earlier. Ethology and Sociobiology, 15, 87-94.

Mazur, A., Mazur, J., \& Keating, C. (1984). Military rank attainment of a West Point class: Effects of cadets' physical features. American Journal of Sociology, 90, 125-150.

McArthur, L. Z., \& Apatow, K. (1983). Impressions of baby-faced adults. Social Cognition, 2, 315-342.

McArthur, L. Z., \& Baron, R. M. (1983). Toward an ecological theory of social perception. Psychological Review, 90, 215-238.

Mealey, L. (2000). Sex differences: Developmental and evolutionary strategies. San Diego, CA: Academic Press.

Mueller, U., \& Mazur, A. (1997). Facial dominance in Homo sapiens as honest signaling of male quality. Behavioral Ecology, 8, 569-579.

Penton-Voak, I. S., Jacobson, A., \& Trivers, R. (2004). Populational differences in attractiveness judgements of male and female faces: Comparing British and Jamaican samples. Evolution and Human Behavior, 25, 355-370.

Penton-Voak, I. S., Little, A. C., Jones, B. C., Burt, D. M., Tiddeman, B. P., \& Perrett, D. I. (2003). Female condition influences preferences for sexual dimorphism in faces of male humans. Journal of Comparative Psychology, 117, 264-271.

Penton-Voak, I. S., \& Perrett, D. I. (2001). Male facial attractiveness: Perceived personality and shifting female preferences for male traits across the menstrual cycle. Advances in the Study of Behavior, 30, 219-259.

Penton-Voak, I. S., Perrett, D. I., Castles, D., Burt, M., Koyabashi, T., \& Murray, L. K. (1999). Female preferences for male faces change cyclically. Nature, 399 , 741-742.

Perrett, D. I., Lee, K. J., Penton-Voak, I. S., Rowland, D. R., Yoshikawa, S., Burt, D. M., et al. (1998). Effects of sexual dimorphism on facial attractiveness. Nature, 394, 884-887.

Raudenbush, S. W., \& Bryk, A. S. (2002). Hierarchical linear models: Applications and data analysis methods. Thousand Oaks, CA: Sage. 
Regan, P. C., Levin, L., Sprecher, S., Christopher, F. S., \& Cate, R. (2000). Partner preferences: What characteristics do men and women desire in their short-term sexual and long-term romantic partners? Journal of Psychology \& Human Sexuality, 12, 1-21.

Rhodes, G., Chan, J., Zebrowitz, L. A., \& Simmons, L. W. (2003). Does sexual dimorphism in human faces signal health? Proceedings of the Royal Society of London, Series B, 270, (Suppl.), S93-S95.

Rowe, D. C., Vazsonyi, A. T., \& Figueredo, A. J. (1997). Mating-effort in adolescence: A conditional or alternative strategy. Personality and Individual Differences, 23, 105-115.

Samuels, C. A., \& Ewy, R. (1985). Aesthetic perception of faces during infancy. British Journal of Developmental Psychology, 3, 221-228.
Scheib, J. (1994). Sperm donor selection and the psychology of female mate choice. Ethology and Sociobiology, 15, 113-129.

Symons, D. (1979). The evolution of human sexuality. Oxford, UK: Oxford University Press.

Zahavi, A. (1975). Mate selection-A selection for a handicap. Journal of Theoretical Biology, 53, 205-213.

Zebrowitz, L. A., Hall, J. A., Murphy, N. A., \& Rhodes, G. (2002). Looking smart and looking good: Facial cues to intelligence and their origins. Personality and Social Psychology Bulletin, 28, 238-249.

Zebrowitz, L. A., \& Rhodes, G. (2004). Sensitivity to "bad genes" and the anomalous face overgeneralization effect: Cue validity, cue utilization, and accuracy in judging intelligence and health. Journal of Nonverbal Behavior, 28, 167-185. 